 \\ Neurocritical
}

\section{Basic considerations on magnesium in the management of neurocritical patients}

Ivan David Lozada-Martinez, MS ${ }^{1,2,3}$; Teddy Javier Padilla-Durán, MD*; Jhon Jairo González-Monterroza, MD; Daniel Alfonso Aguilar-Espinosa, MD; Kelly Nathalia Molina-Perea, MD ${ }^{6}$; William Camargo-Martinez, MS ; Luz Llamas-Medrano, MS ${ }^{1}$; Mariana Hurtado-Pinillos, $\mathrm{MS}^{7}$; Alejandra Guerrero-Mejía, $\mathrm{MD}^{8}$; Tariq Janjua, $\mathrm{MD}^{9}$; Luis Rafael Moscote-Salazar, MD, PhD(c) ${ }^{1,2,3}$

\author{
${ }^{1}$ Medical and Surgical Research Center, Cartagena, Colombia \\ ${ }^{2}$ Colombian Clinical Research Group in Neurocritical Care, School of Medicine, University of \\ Cartagena, Cartagena, Colombia \\ ${ }^{3}$ Latin American Council of Neurocritical Care, Cartagena, Colombia \\ ${ }^{4}$ School of Medicine, Universidad del Magdalena, Santa Marta, Colombia \\ ${ }^{5}$ School of Medicine, Universidad de la Sabana, Chía, Colombia \\ ${ }^{6}$ School of Medicine, Fundación Universitaria Juan N Corpas, Bogotá, Colombia \\ ${ }^{7}$ Colombian Clinical Research Group in Neurocritical Care, School of Medicine, Fundación \\ Universitaria Autonoma de las Americas, Pereira, Colombia \\ ${ }^{8}$ School of Medicine, Universidad de Manizales, Manizales, Colombia \\ ${ }^{9}$ Department of Intensive Care, Regions Hospital, St Paul, MN, USA
}

REVIEW ARTICLE

Received: June 21, 2021
Revised: August 6, 2021
Accepted: August 12, 2021

Corresponding Author: Ivan David Lozada-Martinez, MS Medical and Surgical Research Center, Las Gaviotas, Primera Etapa, Manzana 37 lote 05. Cartagena 130004, Colombia Tel: +57-31-5779-9823 Fax: +57-31-5779-9823 E-mail: ilozadam@unicartagena.edu.co

Magnesium is an essential chemical element in human life. In the brain, it is physiologically responsible for a large number of processes involved in intracellular homeostasis, blood-brain barrier integrity, protein synthesis, neuronal proliferation, aging, and apoptosis. Considering that neurocritical care is a relatively new discipline in certain regions of the world and is an independent protective factor of neurological diseases in critical care, it is essential to disseminate basic concepts and utilities of tools that can positively impact the neurological disease burden. Magnesium and its use in neurocritical care are poorly understood. Therefore, this study aimed to review basic concepts regarding the physiology of magnesium in neurological dynamics, its role in the pathophysiology of neurological disorders, and the outcome of its use in the management of neurocritical illnesses.

Keywords: Magnesium; Magnesium deficiency; Physiology; Nervous system diseases; Neurocritical care

\section{INTRODUCTION}

Magnesium $(\mathrm{Mg})$ is a chemical element that is essential for human life. In the brain, it is physiologically responsible for many processes involved in intracellular homeostasis, blood-brain barrier integrity, protein synthesis, neuronal proliferation, aging, and apoptosis [1]. This element is also a special target of research and clinical monitoring [2] as it is associated with memory and learning [3], headache and migraine [4], cerebral edema [4], stroke [5], and traumatic brain injury [6], among many other neurological disorders [1-4]; therefore, knowledge regarding $\mathrm{Mg}$ in neurocritical care is crucial. However, there is a paucity of literature on the role of this cation in physiological and pathophysiological mechanisms that occur in neuronal dynamics. Although the num-

C 2021 The Korean Neurocritical Care Society

This is an Open Access article distributed under the terms of the Creative Commons Attribution Non-Commercial License (http://creativecommons.org/licenses/by-nc/4.0/) which permits unrestricted noncommercial use, distribution, and reproduction in any medium, provided the original work is properly cited. 
ber of studies is few, the results obtained are interesting.

Considering that neurocritical care is a relatively new discipline in certain regions of the world $[7,8]$ and that it is an independent protective factor for neurological diseases in critical care $[9,10]$, the dissemination of basic concepts and utilities of tools that can positively impact the burden of neurological diseases that occur mainly in low- and middle-income countries is essential [11], especially due to cerebrovascular disease and neurotrauma [11]. In the published literature, most of the studies that have evaluated the usefulness of $\mathrm{Mg}$ in neurocritical care have focused on the management of subarachnoid hemorrhage [12-17], neurocritical complications during pregnancy and puerperium $[18,19]$, and traumatic brain injury [20-22], and its use in other conditions of great interest, such as seizures and epilepsy is unknown, neuromuscular disorders, metabolic encephalopathies and delirium, neuroendocrine diseases, neurogenetic diseases, neuropsychiatric disorders [3], and non-neurological complications in neurocritical patients, which implies a wide knowledge gap between $\mathrm{Mg}$ and neurocritical care.

Understanding neurological physiology from the most basic aspects (at the molecular level) and seeking solutions in translational metabolomics research [2] will help in improving outcomes in the management of neurocritical pathologies to improve the quality of care of these patients, providing patient and family satisfaction, and reducing costs in acute care, as well as in neurorehabilitation and disability. In this order of ideas, the objective of this manuscript is to review basic concepts on the physiology of $\mathrm{Mg}$ in neurological dynamics, its role in the pathophysiology of neurological disorders, and the results of its use in the management of neurocritical diseases.

\section{BASIC ASPECTS OF MAGNESIUM PHYSIOLOGY IN THE CENTRAL NERVOUS SYSTEM}

\section{Role of magnesium in cell dynamics}

$\mathrm{Mg}$ has been described as an indispensable chemical element in the maintenance of cellular dynamics as it is associated with several enzymatic reactions that regulate cellular metabolism and protein synthesis [23]. This mineral is absorbed in the gastrointestinal tract and kidneys and its serum level, together with that of calcium $(\mathrm{Ca})$, is increased by parathormone [3]. Its free concentrations do not correlate with the total body concentration, as approximately $1 \%$ of this mineral is found in the extracellular fluid [24]. Among its different forms, ionized Mg is the most biologically active [24].

$\mathrm{Mg}$ facilitates organic activities in the neuromuscular system, such as neuronal and muscular excitability, contractibility, and rhythm in the cardiovascular system, and vasodilatation in the circulatory system [25-27]. More specifically, in the brain, it is responsible for intracellular transmission, myelination, synapse formation and maintenance, and regulation of cholinergic, dopaminergic, and serotonergic transmission (through the decrease of acetylcholine release at the neuromuscular junction; blockade of $\mathrm{N}$-methyl-D-aspartate (NMDA) receptors, inhibiting the excitatory function of glutamate, and stimulation of GABA receptors generating neuronal hyperpolarization, and exerting an inhibitory effect in the process) [28-31]. It is also involved in the release of calcitonin gene-related peptide (neuropeptide). It decreases the release of substance $P$, induces the secretion of inflammatory mediators, such as tumor necrosis factor $\alpha$ and interleukin 1 , and intervenes in the mitigation of neuroinflammatory processes $[32,33]$.

Therefore, it is directly involved in the maintenance of neurological integrity, neuroprotection against apoptosis in situations of hypoxia-ischemia, prevention of synapse loss in neurodegeneration, promotion of neurogenetic activities, proliferation of neural stem cells, and neuromaturation [1-4,32]. Likewise, it plays a fundamental role in neuroplasticity, and precisely because of this, research on this element and its impact on the acute management and neurorehabilitation of neurological disorders is important [34]. However, it is first necessary to know the neurometabolic processes that enable the establishment of hypotheses with biological plausibility and the prediction outcomes in biological and human models.

\section{Magnesium and the blood-brain barrier}

The blood-brain barrier is a highly selective semi-permeable border of endothelial cells that prevents solutes in the circulating blood from crossing non-selectively into the extracellular fluid of the central nervous system, where neurons reside [35]. In the brain, there are two main associated fluid compartments: the extracellular fluid, which surrounds neurons and glial cells, and the cerebrospinal fluid, which is located in the subarachnoid space and ventricles of the brain [36]. The passage of $\mathrm{Mg}$ through this barrier is made possible by a complex system of genes and proteins [1].

Animal studies have shown that $\mathrm{Mg}$ can cross the blood-brain barrier and is transported across the barrier with a net flow from the blood to the parenchyma [37-39]. The active transport of $\mathrm{Mg}$ from the blood to the extracellular fluid of the brain is evidenced by its higher concentration in the extracellular cortical fluid than in the plasma dialysate or cisternal cerebrospinal fluid [38,39]. Another interesting finding is that $\mathrm{Mg}$ administration could atten- 
uate cell death secondary to alterations in the cytoskeleton and, therefore, reduce apoptosis due to 553 expression after brain trau$\mathrm{ma}[1]$.

Concerning the association between $\mathrm{Mg}$ and brain edema, it has been proposed that $\mathrm{Mg}$ supplementation decreases regional brain tissue water content, attenuates brain edema formation after trauma, protects the blood spinal cord blood, improves clinical recovery, and preserves normal spinal cord ultrastructure in the case of experimental spinal cord injury in rats [1,40-42]. This has been demonstrated in experimental studies focused on the treatment of cerebral edema that sought to demonstrate the benefits of Mg administered in combination with various pharmacological drugs in animal models and its possible role in the resolution of cerebral edema [43]. They revealed that increased aquaporin-4 (AQP-4), which is a bidirectional transmembrane water channel believed to play a role in brain injury by contributing to increased brain water content, could result in cerebral edema $[40,41]$.

In this order of ideas, and given that $\mathrm{Mg}$ supplementation causes the downregulation of AQP-4 [40,41], Mg is able to exert beneficial effects in neurocritical conditions (Fig. 1). Furthermore, it also exerts neuroprotective effects in anoxic insults by enhancing the recovery of synaptic transmission and blocking the loss of protein kinase C [42], restricting the opening of paracellular pathways through $\mathrm{Ca}$ antagonism, alleviating oxidative stress, and preventing hypertensive encephalopathy by reducing the cerebral perfusion pressure [1].

\section{MAGNESIUM ALTERATIONS AND MOLECULAR PATHOPHYSIOLOGICAL MECHANISMS}

\section{Hypomagnesemia}

Hypomagnesemia is defined as a plasma $\mathrm{Mg}$ concentration of $<1.7 \mathrm{mg} / \mathrm{dL}[44,45]$. The clinical manifestations of hypomagnesemia are nonspecific since hypomagnesemia is associated with hypocalcemia and hypokalemia in many cases [44-46]. The causes of hypomagnesemia can be classified according to their pathophysiology, as follows: (1) decreased intake; (2) redistribution secondary to an increase in the passage of $\mathrm{Mg}$ from the extracellular to the intracellular space (present in pathologies such as hyperparathyroidism, hyperthyroidism, etc.); (3) gastrointestinal losses (diarrhea, vomiting, or surgical resection of the intestine); and (4) renal losses [44-47]. However, given that serum Mg concentration is not usually requested as part of routine blood tests, it should be kept in mind and its measurement should be requested directly in clinical situations that could possibly be associated with alterations in its homeostasis [48].

Among the clinical manifestations of hypomagnesemia are cardiac arrhythmias, which are the most important, and neuromuscular alterations, such as convulsions, paresthesia, nystagmus, Chvostek's sign, and positive Trousseau's sign [44-48]. A curious fact is that between $40 \%$ and $60 \%$ of patients with hypokalemia also have hypomagnesemia. This is because there are

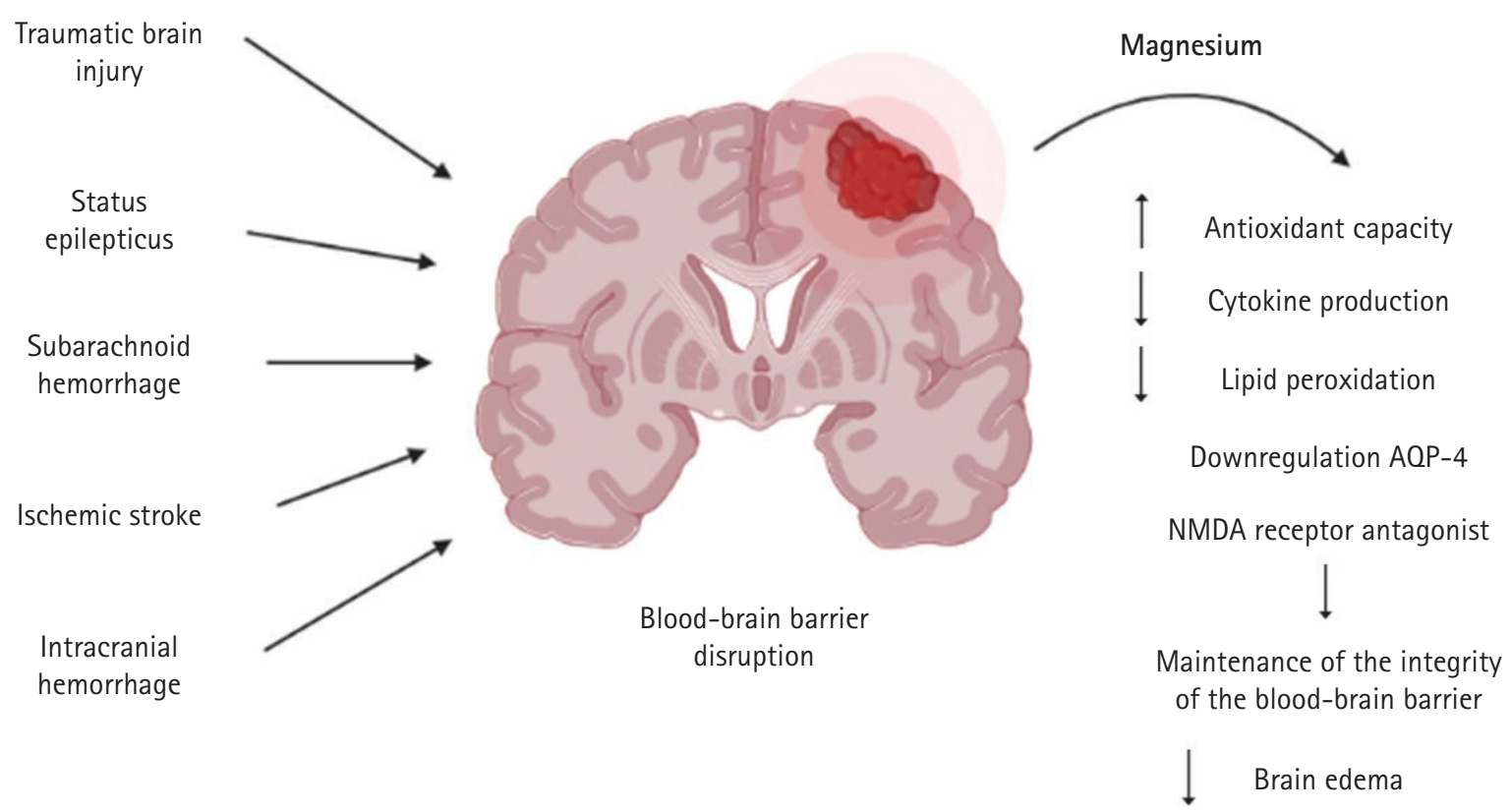

Fig. 1. Neuroprotective mechanisms of magnesium against blood-brain barrier disruption. NMDA, N-methyl-D-aspartate; AQP-4, aquaporin-4. Created by the authors using BioRender. 
different circumstances specific to the patient that cause the loss of both $\mathrm{Mg}$ and potassium, including gastrointestinal losses (diarrhea) and the chronic use of diuretics, such as furosemide $[45,46]$.

As for treatment, it is known that in cases where plasma $\mathrm{Mg}$ deficiency is severe ( $<1 \mathrm{mEq} / \mathrm{L}$ in serum), or symptomatic with clinical manifestations of neuromuscular, neurological, or cardiac arrhythmias, the Mg repletion should be achieved by prompt intravenous administration of $2 \mathrm{~g}$ of magnesium sulfate $\left(\mathrm{MgSO}_{4}\right)$ in $100 \mathrm{~mL}$ of D5W for 5 to 10 minutes, followed by a continuous infusion of 4 to $6 \mathrm{~g} /$ day for 3 to 5 days (only in the case where the renal function remains relatively normal and stable) while treating the underlying cause of the $\mathrm{Mg}$ deficiency to prevent future recurrence in the case where it is secondary to another pathology [44-48]. As for maintenance therapy, oral administration of $\mathrm{Mg}$ oxide ( $400 \mathrm{mg}$ twice a day or three times a day) can be used as long as the risk factors for $\mathrm{Mg}$ deficiency are maintained [44-48].

\section{Hypermagnesemia}

Hypermagnesemia is defined as a serum $\mathrm{Mg}$ level of $>2.2 \mathrm{mg} / \mathrm{dL}$. This entity is very rare; however, it can occur iatrogenically when intravenous $\mathrm{MgSO}_{4}$ is being administered in patients with chronic renal disease or in those who chronically ingest $\mathrm{Mg}$-containing laxatives [48,49].

The clinical manifestations of intoxication will depend on the level of Mg in plasma; as such, in the case of mild hypermagnesemia, it may even be asymptomatic. Therefore, its clinical manifestations may only appear with levels above $2.5 \mathrm{mmol} / \mathrm{L}$ $[50,51]$. The clinical manifestations of hypermagnesemia include oliguria (2.5\%), loss of patellar reflex (1.6\%), cardiac conduction disturbance, respiratory depression, and cardiorespiratory arrest [52]. However, certain studies suggest that hypermagnesemia is associated with an increased need for vasopressor drugs, increased risk of respiratory failure, and increased mortality [48-52].

Serious gastrointestinal manifestations may also arise as a cause of this pathology, such as the association of hypermagnesemia with the presence of toxic megacolon or ischemic colitis due to altered intestinal circulation, possibly leading to local ischemia due to decreased intestinal motility caused by fecal impaction and increased intraluminal pressure that could be aggravated if accompanied by prolonged hypotension [48-53]. The treatment of intoxication is based on adequate hydration, increasing renal excretion through the use of diuretics, and the administration of $1 \mathrm{~g}$ of the antidote (Ca chloride or Ca gluconate) [49-52].

\section{MAGNESIUM AND NEUROLOGICAL DISORDERS}

\section{Status epilepticus}

There is extensive experience regarding the use of $\mathrm{MgSO}_{4}$ infusion in eclampsia seizures; however, there are few studies supporting the effectiveness of this drug in status epilepticus and super-refractory status epilepticus [54-56].

During these states, the NMDA receptor is overregulated, leading to glutamate hit-toxicity and seizure potentiation. Because this receptor plays a key role in drug resistance and the genesis of status epilepticus of status epilepticus and super-refractory status epilepticus, NMDA receptor antagonists have been studied as anticonvulsants of choice for these pathologies [54-56].

Previous studies have shown that the use of $\mathrm{MgSO}_{4}$ as an NMDA receptor antagonist at a dose of $4 \mathrm{~g}$, followed by a continuous infusion at a rate of $2-6 \mathrm{~g} / \mathrm{hr}$, safely increases plasma $\mathrm{Mg}$ levels by $3.5 \mathrm{mmol} / \mathrm{L}$, with positive results for this group of patients [54-56].

\section{Intracranial hemorrhage}

Intracranial hemorrhage is considered the second most common type of stroke, with the lowest percentage improvement in mortality and morbidity among all strokes. It occurs in two stages: the first consists of the growth and stabilization of an initial hematoma that appears acutely, and the second consists of the expansion of the perihematoma edema and its irruption into the blood-brain barrier [5,57-59].

$\mathrm{Mg}$ has been reported to prevent hematoma formation in both stages due to three of its specific properties [57-59]: (1) Its vasodilator function is achieved thanks to its property as a Ca channel antagonist, which prevents the entry of $\mathrm{Ca}$ and its release by the sarcoplasmic reticulum. Its function as an angiotensin-converting enzyme inhibitor and its capacity to increase prostacyclin production also play a role. This vasodilator effect favors the lowering of blood pressure, which attenuates the volume of the hematoma and its progression to intracranial hemorrhage [57-59]. (2) Its ability to promote hemostasis: This cation acts as a substantial cofactor in hemostasis by increasing $\mathrm{Ca}^{2+}$ binding to factor IX, stabilizing its binding, and promoting the activation of factor IX by factor Xia. It promotes the interaction between tissue factor and the $\gamma$-carboxyglutamate-rich domain of factor $X[57,58]$. (3) Its ability to preserve the blood-brain barrier: Functioning as an NMDA receptor antagonist potentiates presynaptic adenosine and inhibits oxidized low-density lipoproteins. Further, it can relax vascular smooth muscles and improve cerebral blood flow. In this way, it acts in the second stage of hemorrhage formation, minimizing he- 
matoma breakthrough to the blood-brain barrier $[57,58]$.

\section{Cerebral vasospasm secondary to aneurysmal subarachnoid hemorrhage}

Cerebral vasospasm occurs in approximately $70 \%$ of patients with aneurysmal subarachnoid hemorrhage, which is the main cause of morbidity and mortality in these patients. This fact has led to research focused on the prevention of vasospasm as a measure to reduce irreversible sequelae in these patients [60-62]. It has been shown that $\mathrm{MgSO}_{4}$ can decrease outcomes in patients with subarachnoid hemorrhage by attenuating vasospasm [1]. This is achieved by different mechanisms, including blockade of NMDA receptors, inhibition of excitatory amino acids, and antagonism of voltage-dependent Ca channels [60-62].

Recent studies have shown that $\mathrm{MgSO}_{4}$ therapy is safe and reduces the incidence of ischemia following subarachnoid hemorrhage vasospasm. It consists of ingesting doses of $64 \mathrm{mmol} /$ day, which would bring serum $\mathrm{Mg}$ to levels of 1-2 mmol/L, which do not represent a risk for the organism [4]. $\mathrm{MgSO}_{4}$ therapy has shown greater effectiveness than other drugs, such as milrinone, by producing greater hypotension with a consequent requirement for dopamine and norepinephrine compared to $\mathrm{Mg}$ [60-62] .

\section{Ischemic stroke}

In 2019, Larsson et al. [63] reported an inverse relationship between serum Mg levels and the risk of cardioembolic stroke, associating hypomagnesemia with a $70 \%-80 \%$ higher risk of suffering from this pathology. The mechanisms through which $\mathrm{Mg}$ contributes to reducing the risk of ischemic stroke are largely explained by its properties: its ability to improve endothelial function, reduce blood pressure, atherosclerotic plaque formation, oxidative stress, insulin resistance, and fasting glycemia. It is also believed to possess qualities that reduce platelet aggregation, decrease thromboxane A2 synthesis, and von Willebrand factor binding $[63,64]$. Mg's ability to affect the dynamics of autoregulation of the cerebral vasculature and its neuroprotective effect by inhibiting the action of NMDA receptors [64] has made this electrolyte one of interest to the stroke research community.

To date, few randomized clinical trials and prospective studies have evaluated the role of $\mathrm{MgSO}_{4}$ in both ischemic and hemorrhagic stroke, mostly using mixed groups (ischemic and hemorrhagic stroke) (Table 1) [63,65-72]. In 2004, one of the first representative studies, a clinical trial with the objective of determining whether the administration of $\mathrm{MgSO}_{4}$ in the prehospital phase of stroke was safe and favorable, was published; in this study, it was observed that neuroprotective activity was indeed observed [65]. However, the total number of patients was 20 , and it was a mixed group (80\% ischemic stroke and 20\% hemorrhagic stroke) [65]. Almost a decade later, Saver et al. [66] conducted a trial with the purpose of evaluating the role of $\mathrm{MgSO}_{4}$ administration time from symptom onset in patients with stroke and long-term functional outcomes. In this study, 1,700 patients who had an ischemic stroke (73.3\%) were enrolled, and the average time of drug administration from symptom onset was 45 minutes; no significant benefits were obtained compared to placebo [66].

In particular, Pan et al. [68] carried out a study in which they evaluated the impact of the oral administration of $\mathrm{Mg}$ and potassium as supplements to table salt on the recovery of stroke patients, observing that out of three groups (salt $[\mathrm{Na}]$, salt $+\mathrm{K}$, and salt $+\mathrm{K}+\mathrm{Mg}$ ), the group that received $\mathrm{Mg}$ supplementation had a more favorable recovery in the neurological evolution of stroke [68]. Unfortunately, other studies have reported non-significant results; however, like those described here, they have limitations and are heterogeneous. In spite of this divergence, the neuroprotective effect of $\mathrm{MgSO}_{4}$ was remarkable. Similar results are evident in studies that used groups of patients with subarachnoid hemorrhage in both the prehospital and hospital phases [70,71].

In a systematic review conducted by Fang et al. [72] that included 40 prospective cohort studies, a $7 \%$ reduced risk of stroke was found in people with high $\mathrm{Mg}$ intake compared to those with low $\mathrm{Mg}$ intake. Recently, the most powerful claims have been in favor of the usefulness of $\mathrm{MgSO}_{4}$ in improving the prognosis of stroke patients. However, it is necessary to continue to propose high-quality studies with a considerable sample size to obtain convincing results [73].

\section{Traumatic brain injury}

The neuroprotective role of $\mathrm{Mg}$ was evidenced in experimental studies by the inhibition of glutamate release, NMDA receptor activation, Ca channel opening, lipid peroxidation, free radical production, edema formation, and the opening of mitochondrial permeability transition pores responsible for apoptosis, such as p53 and $B a x$ [74-77].

Hypomagnesemia in patients with severe traumatic brain injury is associated with an increase in negative outcomes, such as mortality and poor functional prognosis [74-77], and adequate control is part of the comprehensive management of patients with severe traumatic brain injury [75]. Lyons and Blackshaw [77] conducted a systematic review and meta-analysis in which they evaluated the impact of $\mathrm{MgSO}_{4}$ in the management of adults with traumatic brain injury, where it was observed that the pooled results of six studies found all-cause mortality to not be significantly different in the treatment group (relative risk, 0.84; 95\% confidence interval, $0.54-1.33 ; \mathrm{p}=0.46$ ) with an $\mathrm{I}^{2}$ value of $>70 \%$. With re- 


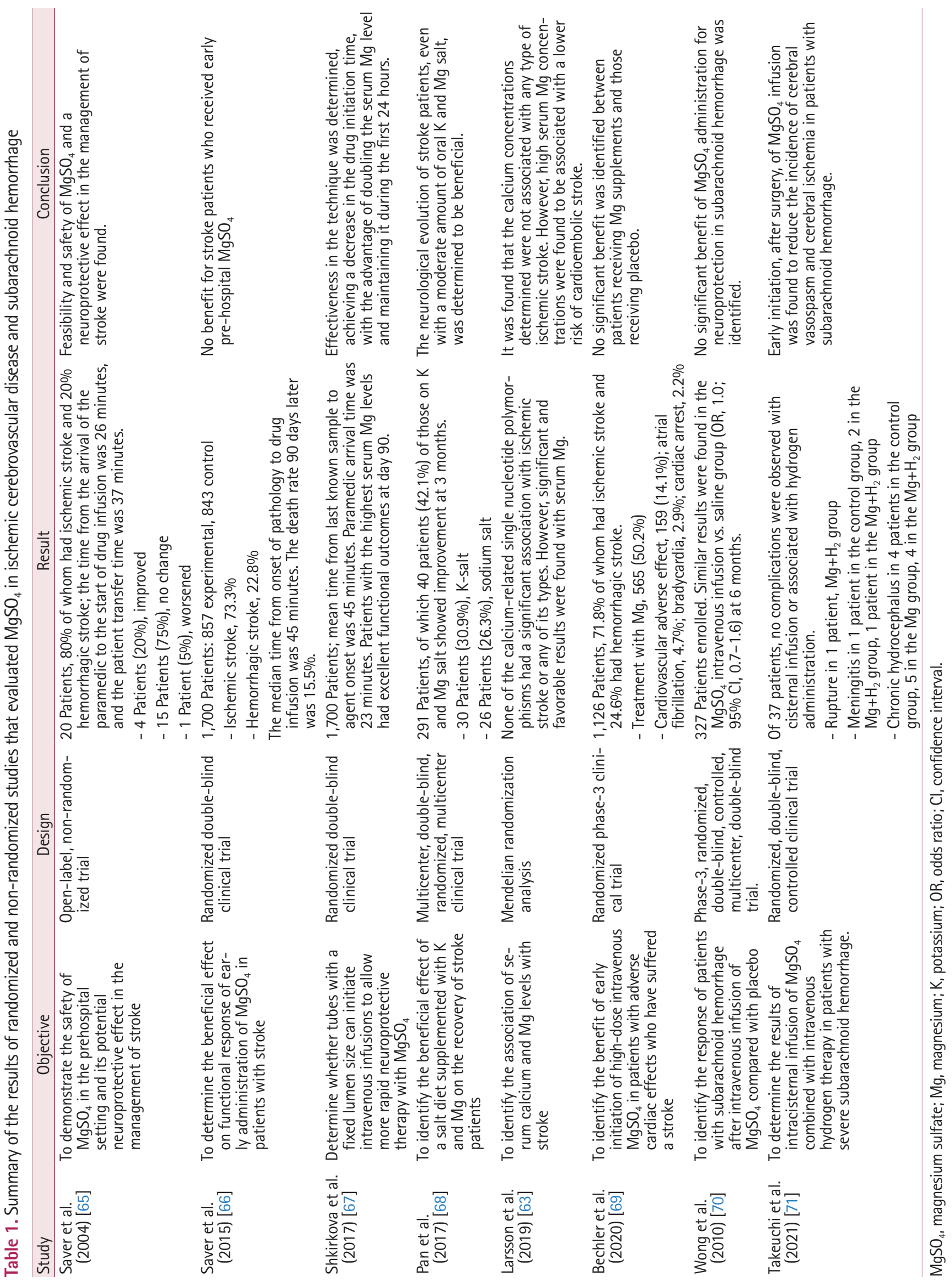


gard to the secondary outcomes, there was no significant difference in the Glasgow Outcome Scale score between the treatment and control groups. It is due to the above that attempts have been made to introduce $\mathrm{MgSO}_{4}$ as a neuroprotective agent with very heterogeneous results so that an accurate clinical recommendation can be given [77].

\section{FUTURE PERSPECTIVES}

Studies on the description of $\mathrm{Mg}$ in the physiology of the central nervous system, as well as its therapeutic utility in neurocritical care, are almost nonexistent at present. It is necessary to come up with new lines of research aimed at exploring the effect of $\mathrm{Mg}$ in central nervous system tumors, acquired metabolic disorders, neurogenetic diseases, neuronutrition, neurorehabilitation, and infectious diseases. Being an affordable mineral, it is postulated as a therapeutic option applicable in low-level healthcare contexts for the stabilization of neurocritical patients while they are being evaluated by a specialized department.

\section{CONCLUSIONS}

In a review of the different neuropathological conditions, a direct relationship between the physiological mechanisms of $\mathrm{MgSO}_{4}$ and multiple pathophysiological phenomena can be observed. Therefore, current evidence allows us to observe that $\mathrm{MgSO}_{4}$ can be an important part of the treatment of this type of pathology. Even so, in certain situations, for greater acceptance of its use, it is necessary to design studies of better quality to optimize the therapeutic objectives and, in this way, be able to obtain standardized schemes in the future for better results in its implementation.

\section{ARTICLE INFORMATION}

\section{Ethics statement}

Not applicable.

\section{Conflict of interest}

No potential conflict of interest relevant to this article.

\section{ORCID}

Ivan David Lozada-Martinez https:/ orcid.org/0000-0002-1960-7334

Teddy Javier Padilla-Durán https://orcid.org/0000-0002-1318-1483

Jhon Jairo González-Monterroza

https://orcid.org/0000-0002-4651-5777

Daniel Alfonso Aguilar-Espinosa

https://orcid.org/0000-0002-8399-6397
Kelly Nathalia Molina-Perea https://orcid.org/0000-0002-5123-9500

William Camargo-Martinez https://orcid.org/0000-0002-9937-9422

LuzLlamas-Medrano

https://orcid.org/0000-0002-9462-8397

Mariana Hurtado-Pinillos https://orcid.org/0000-0002-4841-5550

Alejandra Guerrero-Mejía https://orcid.org/0000-0003-3998-2649

TariqJanjua

https://orcid.org/0000-0001-5852-0090

Luis Rafael Moscote-Salazar https://orcid.org/0000-0002-4180-6962

\section{Author contributions}

Conceptualization: all authors. Data Curation: IDLM, TJPD, JJGM, DAAE, KNMP, WCM, LLM, MHP, AGM. Formal analysis: IDLM, TJPD, JJGM, DAAE, KNMP, WCM, LLM, MHP, AGM. Methodology: all authors. Project administration: all authors. Visualization: IDLM, LRMS, TJ, YAPJ. Writing-original draft: all authors. Writing-review \& editing: all authors.

\section{REFERENCES}

1. Vink R, Nechifor M. Magnesium in the central nervous system. Adelaide: University of Adelaide Press; 2011.

2. Wolahan SM, Hirt D, Glenn TC. Translational metabolomics of head injury: exploring dysfunctional cerebral metabolism with ex vivo NMR spectroscopy-based metabolite quantification. In: Kobeissy FH, eds. Brain neurotrauma: molecular, neuropsychological, and rehabilitation aspects. Boca Raton, FL: CRC Press/ Taylor \& Francis; 2015.

3. Botturi A, Ciappolino V, Delvecchio G, Boscutti A, Viscardi B, Brambilla $P$. The role and the effect of magnesium in mental disorders: a systematic review. Nutrients 2020;12:1661.

4. Xue W, You J, Su Y, Wang Q. The effect of magnesium deficiency on neurological disorders: a narrative review article. Iran J Public Health 2019;48:379-87.

5. Chang JJ, Armonda R, Goyal N, Arthur AS. Magnesium: pathophysiological mechanisms and potential therapeutic roles in intracerebral hemorrhage. Neural Regen Res 2019;14:1116-21.

6. Maas AI, Murray GD. Magnesium for neuroprotection after traumatic brain injury. Lancet Neurol 2007;6:20-1.

7. Kramer AH, Couillard P. Neurocritical care: a growing international collaborative. Neurocrit Care 2020;32:80-3.

8. Porcayo-Liborio S, Rivera-Durón E, Orta-San-Juan D. The evolution of neuro-critical care in Mexico. Rev Mex Anest 2010;33: 50-5.

9. Suarez JI, Zaidat OO, Suri MF, Feen ES, Lynch G, Hickman J, et al. Length of stay and mortality in neurocritically ill patients: impact of a specialized neurocritical care team. Crit Care Med 2004;32:2311-7.

10. Varelas PN, Conti MM, Spanaki MV, Potts E, Bradford D, Sun- 
strom C, et al. The impact of a neurointensivist-led team on a semiclosed neurosciences intensive care unit. Crit Care Med 2004;32:2191-8.

11. World Health Organization. Global burden of neurological disorders: estimates and projections [Internet]. Geneva: World Health Organization; 2007 [cited 2021 Jun 14]. Available from: https://www.who.int/mental_health/neurology/chapter_2_ neuro_disorders_public_h_challenges.pdf.

12. Amory CF, Varelas PN. Magnesium and hydrogen in subarachnoid hemorrhage: is neuroprotection finally a reality? Stroke 2021;52:28-30.

13. Dorhout Mees SM, Algra A, Vandertop WP, van Kooten F, Kuijsten HA, Boiten J, et al. Magnesium for aneurysmal subarachnoid haemorrhage (MASH-2): a randomised placebo-controlled trial. Lancet 2012;380:44-9.

14. van den Bergh WM, Dijkhuizen RM, Rinkel GJ. Potentials of magnesium treatment in subarachnoid haemorrhage. Magnes Res 2004; 17:301-13.

15. van den Bergh WM, Algra A, van Kooten F, Dirven CM, van Gijn J, Vermeulen M, et al. Magnesium sulfate in aneurysmal subarachnoid hemorrhage: a randomized controlled trial. Stroke 2005;36:1011-5.

16. Venkatasubba Rao CP, Suarez JI. Magnesium and neuroprotection in subarachnoid haemorrhage. Lancet 2012;380:9-11.

17. Wong GK, Poon WS. Magnesium sulphate for aneurysmal subarachnoid hemorrhage: why, how, and current controversy. Acta Neurochir Suppl 2013;115:45-8.

18. Altman D, Carroli G, Duley L, Farrell B, Moodley J, Neilson J, et al. Do women with pre-eclampsia, and their babies, benefit from magnesium sulphate? The Magpie trial: a randomised placebo-controlled trial. Lancet 2002;359:1877-90.

19. Belfort MA, Anthony J, Saade GR, Allen JC Jr, Nimodipine Study Group. A comparison of magnesium sulfate and nimodipine for the prevention of eclampsia. N Engl J Med 2003; 348:304-11.

20. McLean RM; Nimodipine Study Group. Magnesium and its therapeutic uses: a review. Am J Med 1994;96:63-76.

21. McKee JA, Brewer RP, Macy GE, Borel CO, Reynolds JD, Warner DS. Magnesium neuroprotection is limited in humans with acute brain injury. Neurocrit Care 2005;2:342-51.

22. Li W, Bai YA, Li YJ, Liu KG, Wang MD, Xu GZ, et al. Magnesium sulfate for acute traumatic brain injury. J Craniofac Surg 2015;26:393-8.

23. Sitzia C, Sterlicchio M, Crapanzano C, Dozio E, Vianello E, Corsi Romanelli MM. Intra-erythrocytes magnesium deficiency could reflect cognitive impairment status due to vascular disease: a pilot study.J Transl Med 2020;18:458.
24. Jahnen-Dechent W, Ketteler M. Magnesium basics. Clin Kidney J 2012;5(Suppl 1):i3-14.

25. Barbosa FT, Barbosa LT, Jucá MJ, Cunha RM. Applications of magnesium sulfate in obstetrics and anesthesia. Rev Bras Anestesiol 2010;60:104-10.

26. Volpe SL. Magnesium in disease prevention and overall health. Adv Nutr 2013;4:378S-383S.

27. Gröber U, Schmidt J, Kisters K. Magnesium in prevention and therapy. Nutrients 2015;7:8199-226.

28. Stangherlin A, O'Neill JS. Signal transduction: magnesium manifests as a second messenger. Curr Biol 2018;28:R1403-5.

29. Seyama T, Kamei Y, Iriyama T, Imada S, Ichinose M, Toshimitsu $\mathrm{M}$, et al. Pretreatment with magnesium sulfate attenuates white matter damage by preventing cell death of developing oligodendrocytes. J Obstet Gynaecol Res 2018;44:601-7.

30. Sun Q, Weinger JG, Mao F, Liu G. Regulation of structural and functional synapse density by L-threonate through modulation of intraneuronal magnesium concentration. Neuropharmacology 2016;108:426-39.

31. Spasov AA, Iezhitsa IN, Kravchenko MS, Kharitonova MV. Features of central neurotransmission in animals in conditions of dietary magnesium deficiency and after its correction. Neurosci Behav Physiol 2009;39:645-53.

32. Yamanaka R, Shindo Y, Oka K. Magnesium is a key player in neuronal maturation and neuropathology. Int J Mol Sci 2019; 20:3439.

33. Matsui Y, Funato Y, Imamura H, Miki H, Mizukami S, Kikuchi $\mathrm{K}$. Visualization of long-term $\mathrm{Mg} 2+$ dynamics in apoptotic cells using a novel targetable fluorescent probe. Chem Sci 2017;8: 8255-64.

34. Ortega-Sierra MG, Durán-Daza RM, Carrera-Patiño SA, Rojas-Nuñez AX, Charry-Caicedo JI, Lozada-Martínez ID. Neuroeducation and neurorehabilitation in the neurosurgical patient: programs to be developed in Latin America and the Caribbean. J Neurosurg Sci 2021 Jun 10 [Epub]. https://doi.org/10.23736/ S0390-5616.21.05439-4.

35. Abbott NJ. Evidence for bulk flow of brain interstitial fluid: significance for physiology and pathology. Neurochem Int 2004; 45:545-52.

36. Abbott NJ, Patabendige AA, Dolman DE, Yusof SR, Begley DJ. Structure and function of the blood-brain barrier. Neurobiol Dis 2010;37:13-25.

37. Abbott NJ, Romero IA. Transporting therapeutics across the blood-brain barrier. Mol Med Today 1996;2:106-13.

38. Allsop TF. Transfer of magnesium across the perfused choroid plexus of sheep. Aust J Biol Sci 1986;39:161-9.

39. Allsop TF, Pauli JV. Magnesium concentrations in the ventricu- 
lar and lumbar cerebrospinal fluid of hypomagnesaemic cows. Res Vet Sci 1985;38:61-4.

40. Agre P, Preston GM, Smith BL, Jung JS, Raina S, Moon C, et al. Aquaporin CHIP: the archetypal molecular water channel. Am J Physiol 1993;265(4 Pt 2):F463-76.

41. Amiry-Moghaddam M, Ottersen OP. The molecular basis of water transport in the brain. Nat Rev Neurosci 2003;4:9911001.

42. Butt AM, Jones HC, Abbott NJ. Electrical resistance across the blood-brain barrier in anaesthetized rats: a developmental study. J Physiol 1990;429:47-62.

43. Bara M, Guiet-Bara A. Potassium, magnesium and membranes: review of present status and new findings. Magnesium 1984;3: 215-25.

44. Martin KJ, González EA, Slatopolsky E. Clinical consequences and management of hypomagnesemia. J Am Soc Nephrol 2009;20:2291-5.

45. Panahi Y, Mojtahedzadeh M, Najafi A, Ghaini MR, Abdollahi $\mathrm{M}$, Sharifzadeh $\mathrm{M}$, et al. The role of magnesium sulfate in the intensive care unit. EXCLIJ 2017;16:464-82.

46. Gragossian A, Bashir K, Friede R. Hypomagnesemia. Treasure Island, FL: StatPearls Publishing; 2021.

47. Pham PC, Pham PA, Pham SV, Pham PT, Pham PM, Pham PT. Hypomagnesemia: a clinical perspective. Int J Nephrol Renovasc Dis 2014;7:219-30.

48. Van Laecke S. Hypomagnesemia and hypermagnesemia. Acta Clin Belg 2019;74:41-7.

49. Broman M, Hansson F, Klarin B. Analysis of hypo- and hypermagnesemia in an intensive care unit cohort. Acta Anaesthesiol Scand 2018;62:648-57.

50. Cascella M, Vaqar S. Hypermagnesemia. Treasure Island, FL: StatPearls Publishing; 2021.

51. Topf JM, Murray PT. Hypomagnesemia and hypermagnesemia. Rev Endocr Metab Disord 2003;4:195-206.

52. Schelling JR. Fatal hypermagnesemia. Clin Nephrol 2000;53: 61-5.

53. Bokhari SR, Siriki R, Teran FJ, Batuman V. Fatal hypermagnesemia due to laxative use. Am J Med Sci 2018;355:390-5.

54. Gomes D, Pimentel J, Bentes C, Aguiar de Sousa D, Antunes AP, Alvarez A, et al. Consensus protocol for the treatment of super-refractory status epilepticus. Acta Med Port 2018;31:598605.

55. Zeiler FA, Matuszczak M, Teitelbaum J, Gillman LM, Kazina CJ. Magnesium sulfate for non-eclamptic status epilepticus. Seizure 2015;32:100-8.

56. Kirkland AE, Sarlo GL, Holton KF. The role of magnesium in neurological disorders. Nutrients 2018;10:730.
57. Macías-Ruíz VS, Cordero-Pérez MB, Vásquez-Cedeño DA, Saltos-Mata F. Factors associated with mortality of spontaneous intraparenchymal cerebral hemorrhage in patients over 50 years of age who attended the teodoro maldonado carbo hospital during the year 2017. Rev Ecuat Neurol 2019;28:10-5.

58. Jafari M, Di Napoli M, Lattanzi S, Mayer SA, Bachour S, Bershad EM, et al. Serum magnesium level and hematoma expansion in patients with intracerebral hemorrhage. J Neurol Sci 2019;398:39-44.

59. Liotta EM, Prabhakaran S, Sangha RS, Bush RA, Long AE, Trevick SA, et al. Magnesium, hemostasis, and outcomes in patients with intracerebral hemorrhage. Neurology 2017;89:8139.

60. Mejía C JA, Niño de Mejía MC, Ferrer Z LE, Cohen MD. Cerebral vasospasm secondary to subarachnoid hemorrhage due to ruptured intracerebral aneurysm. Rev Colomb Anesthesiol 2007;35:143-62.

61. Soliman R, Zohry G. Effect of magnesium sulphate and milrinone on cerebral vasospasm after aneurysmal subarachnoid hemorrhage: a randomized study. Braz J Anesthesiol 2019; 69:64-71.

62. Findlay JM, Nisar J, Darsaut T. Cerebral vasospasm: a review. Can J Neurol Sci 2016;43:15-32.

63. Larsson SC, Traylor M, Burgess S, Boncoraglio GB, Jern C, Michaëlsson $\mathrm{K}$, et al. Serum magnesium and calcium levels in relation to ischemic stroke: Mendelian randomization study. Neurology 2019;92:e944-50.

64. Lai TW, Zhang S, Wang YT. Excitotoxicity and stroke: identifying novel targets for neuroprotection. Prog Neurobiol 2014; 115:157-88.

65. Saver JL, Kidwell C, Eckstein M, Starkman S; FAST-MAG Pilot Trial Investigators. Prehospital neuroprotective therapy for acute stroke: results of the Field Administration of Stroke Therapy-Magnesium (FAST-MAG) pilot trial. Stroke 2004;35: e106-8.

66. Saver JL, Starkman S, Eckstein M, Stratton SJ, Pratt FD, Hamilton $\mathrm{S}$, et al. Prehospital use of magnesium sulfate as neuroprotection in acute stroke. N EnglJ Med 2015;372:528-36.

67. Shkirkova K, Starkman S, Sanossian N, Eckstein M, Stratton S, Pratt F, et al. Paramedic initiation of neuroprotective agent infusions: successful achievement of target blood levels and attained level effect on clinical outcomes in the FAST-MAG pivotal trial (field administration of stroke therapy-magnesium). Stroke 2017;48:1901-7.

68. Pan WH, Lai YH, Yeh WT, Chen JR, Jeng JS, Bai CH, et al. Intake of potassium- and magnesium-enriched salt improves functional outcome after stroke: a randomized, multicenter, 
double-blind controlled trial. Am J Clin Nutr 2017;106:126773.

69. Bechler K, Shkirkova K, Saver JL, Starkman S, Hamilton S, Liebeskind DS, et al. The effect of early treatment with intravenous magnesium sulfate on the incidence of cardiac comorbidities in hospitalized stroke patients. Cardiovasc Ther 2020; 2020:1494506.

70. Wong GK, Poon WS, Chan MT, Boet R, Gin T, Ng SC, et al. Intravenous magnesium sulphate for aneurysmal subarachnoid hemorrhage (IMASH): a randomized, double-blinded, placebo-controlled, multicenter phase III trial. Stroke 2010;41:9216.

71. Takeuchi S, Kumagai K, Toyooka T, Otani N, Wada K, Mori K. Intravenous hydrogen therapy with intracisternal magnesium sulfate infusion in severe aneurysmal subarachnoid hemorrhage. Stroke 2021;52:20-7.

72. Fang X, Wang K, Han D, He X, Wei J, Zhao L, et al. Dietary magnesium intake and the risk of cardiovascular disease, type 2 diabetes, and all-cause mortality: a dose-response meta-analysis of prospective cohort studies. BMC Med 2016;14:210.

73. Xu R, Wang L, Sun L, Dong J. Neuroprotective effect of magnesium supplementation on cerebral ischemic diseases. Life Sci 2021;272:119257.

74. Lee JS, Han YM, Yoo DS, Choi SJ, Choi BH, Kim JH, et al. A molecular basis for the efficacy of magnesium treatment following traumatic brain injury in rats. J Neurotrauma 2004;21:54961.

75. Stippler M, Fischer MR, Puccio AM, Wisniewski SR, Carson-Walter EB, Dixon CE, et al. Serum and cerebrospinal fluid magnesium in severe traumatic brain injury outcome. J Neurotrauma 2007;24:1347-54.

76. Godoy DA, Pahnke P, Piñero GR, Videtta W, Aguilera S. Intensive care in severe cranioencephalic trauma. Neurociencias Colomb 2016;23:193-220.

77. Lyons MW, Blackshaw WJ. Does magnesium sulfate have a role in the management of severe traumatic brain injury in civilian and military populations? A systematic review and meta-analysis. J R Army Med Corps 2018;164:442-9. 